\title{
Short term clinical outcomes and analysis of risk factors for pacemaker implantation: a single center experience of self- expandable TAVI valves
}

Simon C. Y. Chow ${ }^{1 *}$ (D), Randolph H. L. Wong ${ }^{1}$, Gary S. H. Cheung ${ }^{2}$, Alex P. W. Lee ${ }^{2}$, Henry K. L. Chui ${ }^{2}$, Kent C. Y. So ${ }^{2}$ and Eugene B. Wu ${ }^{2}$

\begin{abstract}
Objectives: Transcatheter aortic valve implantation is a recognized treatment for patients with severe aortic stenosis at all risk groups. However, permanent pacemaker rates remain high for self expandable transcatheter valves and permanent pacemaker implantation has been associated with increased morbidity. In this analysis we aim to evaluate short term clinical outcomes post self expandable transcatheter aortic valve implantation and determine risk factors for permanent pacemaker implantation.

Methods: 88 patients with severe aortic stenosis with transcatheter aortic valve implantation performed between the year 2016-2018 were retrospectively analyzed. Outcomes of interest included 1- year all cause mortality, 30-day major adverse cardiovascular events, permanent pacemaker and paravalvular leak rates. Survival analysis was performed with Kaplan Meier analysis and risk factors for survival and permanent pacemaker rates were identified with log rank test and regression analysis.

Results: The mean age of the cohort was $80.3+/-6.9$ years. The mean STS score was 9.25 . The 30 day all-cause mortality was $5.7 \%$ and 1-year all cause mortality was 16.7\%. 80 patients had transfemoral transcatheter aortic valve implantation, and a majority of the patients (85.2\%) were implanted with Corevalve Evolut R device. The device success rate was $88.6 \%$. Multivariate analysis identified concomitant severe coronary artery disease $(\mathrm{OR}=18.2+/-$ 0.9; $P=0.002)$, pre transcatheter aortic valve implantation atrial fibrillation $(\mathrm{OR}=8.6+/-0.91 ; P=0.02)$ and post procedural disabling stroke $(\mathrm{OR}=32.6+/-1.35 ; P=0.01)$ as risk factors for 1 -year mortality. The 30 -day pacemaker rate was $17.6 \%$. The presence of right bundle branch block (OR $11.1+/-0.86 ; P=0.005)$, non-coronary cusp implantation depth $(\mathrm{OR}=1.34+/-0.15 ; P=0.05)$ and a non coronary cusp implantation depth / membranous septal length ratio of more than $50 \%$ were associated with post procedural pacemaker implantation $(\mathrm{OR}=29.9+/-$ $1.72 ; P=0.05)$. Among the 15 patients with post procedural pacemaker implantation, $40 \%$ were found to be nonpacemaker dependent at 1 year.

(Continued on next page)
\end{abstract}

\footnotetext{
* Correspondence: wwjdsimon@gmail.com

'Division of Cardiothoracic Surgery, Department of Surgery, The Chinese

University of Hong Kong, Prince of Wales Hospital, 30-32 Ngan Shing Street,

Shatin, New Territories, Hong Kong

Full list of author information is available at the end of the article
}

C C The Author(s). 2020 Open Access This article is licensed under a Creative Commons Attribution 4.0 International License, which permits use, sharing, adaptation, distribution and reproduction in any medium or format, as long as you give appropriate credit to the original author(s) and the source, provide a link to the Creative Commons licence, and indicate if changes were made. The images or other third party material in this article are included in the article's Creative Commons licence, unless indicated otherwise in a credit line to the material. If material is not included in the article's Creative Commons licence and your intended use is not permitted by statutory regulation or exceeds the permitted use, you will need to obtain permission directly from the copyright holder. To view a copy of this licence, visit http://creativecommons.org/licenses/by/4.0/ The Creative Commons Public Domain Dedication waiver (http://creativecommons.org/publicdomain/zero/1.0/) applies to the data made available in this article, unless otherwise stated in a credit line to the data. 
(Continued from previous page)

Conclusion: Short term outcomes of transcatheter aortic valve implantation in severe aortic stenosis patients are promising. Pacemaker rates remain high. More studies are needed to evaluate the factors that influence pacemaker rates and dependence to further improve transcatheter aortic valve implantation outcomes.

Keywords: Aortic valve stenosis, Transcatheter aortic valve implantation , Cardiac pacemaker, Outcome studies

\section{Introduction}

The emergence of Transcatheter aortic valve implantation (TAVI) has revolutionized the treatment of patients with severe aortic stenosis (AS). The Partner III trial and the Evolut $\mathrm{R}$ low risk trial have demonstrated superiority and equipoise of TAVI over surgical aortic valve replacement (SAVR) with respect to short term survival and procedural outcomes, and has firmly established TAVI as an acceptable and effective treatment of severe AS in patients at low risk for SAVR [1, 2]. However, we cannot discount the fact that the aforementioned trials have only included highly selective patients and the majority of the population are elderly with mean age more than 70 years old. The role of TAVI in younger patients is less clear, as important issues such as valve durability,the need for permanent pacemakers (PPM) and bicuspid aortic valves remain to be studied and substantiated [3]. Specifically, the need for PPM post TAVI is particularly important given the added morbidity and negative impact on survival a permanent pacemaker entails to younger patients with life expectancy of more than 10 years. The reported risk of PPM post TAVI range from 10 to $30 \%[4,5]$ irrespective of the type of valve implanted and this rate is much higher than that of SAVR at 3-6\% [6]. In our retrospective analysis, we aim to evaluate short term outcomes and efficacy of selfexpandable (SE) TAVI valves in our center and identify associating factors that influence PPM rates post TAVI.

\section{Materials and methods}

Between 2016 and 2018, 88 patients underwent TAVI in the Prince of Wales Hospital, Hong Kong. These patients were selected from a local cardiac surgery registry and relevant clinical and radiological data were retrospectively extracted from electronic and paper records for further analysis. All patients were considered not candidates for SAVR by a multidisciplinary HEART team. This cardiac surgical local registry was approved by the Hong Kong Hospital Authority and the Government of Hong Kong SAR to allow collection, analysis, reporting and outcome tracking of patient data since its introduction in 2007. No informed consents from patients were sought for this retrospective analysis as there were no identifiers in this manuscript that could disclose individual patient confidentiality. All patient data had been secured and kept confidential.
The outcomes of interest were consistent with the standardized definitions reported by the VARC 2 consortium [7]. Our results and analysis consisted of evaluation of survival outcomes and major TAVI complications including major vascular complications, para-valvular leak (PVL) and PPM rates. In terms of survival analysis, the outcomes of interest were 30 day and 1 year all cause mortality post TAVI. Procedural related death was defined as deaths within 30 days of TAVI. Cardiovascular mortality was defined as deaths relating to any cardiac or vascular events, which included myocardial infarction, cardiac pump failure, arrhythmias, vascular complications, cerebrovascular disease, sudden or unwitnessed death and death of unknown cause. Procedural related stroke was defined as a modified Rankin (mRS) score of 2 or more at 30 days post TAVI or increase in 1 category from baseline.

Procedural records were reviewed, and peri-operative data were retrospectively recorded and analysed. Important intraoperative data were retrieved which included the infra-annular membranous septal (IMS) length, implantation depth at the non-coronary (NCC) (Fig. 1) and left coronary cusps (LCC) on fluoroscopy. The membranous septal length was measured from pre-TAVI ECG-gated computed tomography images at coronal view with no angulation, as defined as the distance between the lowest margin of the annulus to the start of the interventricular septum (Fig. 2). The ratio between the NCC implantation depth on implantation angle and the IMS length was calculated. Successful device implantation was defined as the absence of procedural related mortality, single valve deployment and the absence of moderate to severe paravalvular leak with a post deployment mean gradient of less than $20 \mathrm{mmHg}$. The need of PPM was considered as procedural related if an indication for PPM arose within 30 days post TAVI. Pacemaker non dependence was defined as 1) absence of admission for pacemaker related dysfunction or hemodynamically unstable arrhythmias; 2) atrial or ventricular pacing percentage ( $\mathrm{Vp}$ or $\mathrm{Ap}$ ) less than $5 \%$ during pacemaker interrogation at 1 year post TAVI; 3) baseline follow up electrocardiogram of native rhythm with rate $>60 \mathrm{bpm}$.

Survival and risk factor analysis was performed using IBM SPSS statistics ${ }^{\oplus}$ Version 25. Continuous variables were presented as mean $+/$ - standard deviation. Categorical variables were expressed as frequencies and 


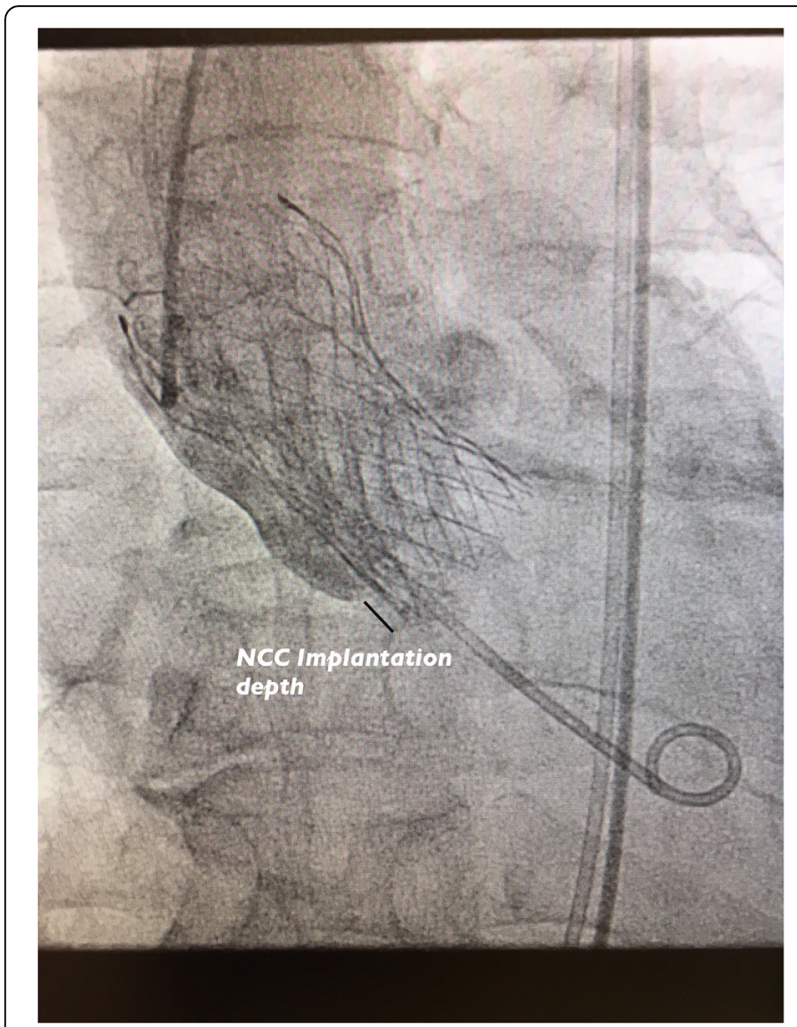

Fig. 1 Implantation depth at NCC at implantation angle during deployment (Black line illustrating implantation depth)

percentages. Kaplan Meier analysis was performed for survival analysis. Univariate analysis of peri- operative factors associated with survival and major complications were analysed with the log rank test and binary logistic regression studies. Significant predictors of mortality or major complications had $P$ values $\leq 0.05$. If more than

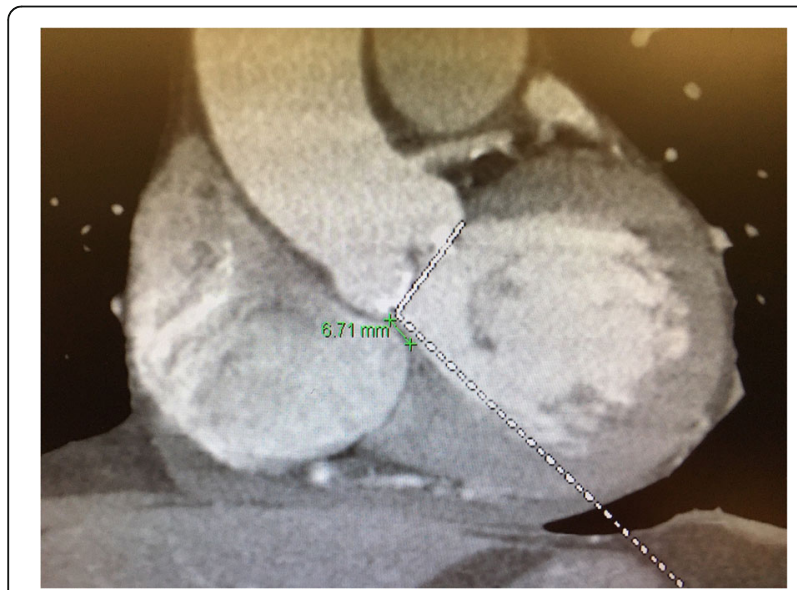

Fig. 2 Measurement of infra-annular membranous septal length (IMS) on coronal cut computed tomography images. Distance measured between lowest point of annulus and start of muscular interventricular septum (Green line with measured dimension of IMS length) one factor was found to be associated with an outcome, multivariate analysis was performed to adjust for confounders.

\section{Results}

\section{Baseline demographics}

Table 1 displays the baseline characteristics of the studied population. 88 patients were selected for 30 day analysis and 84 patients had data for 1 year analysis. The mean age of the population was $80.3+/-6.9$ years. The mean STS predicted risk of mortality score was 9.25 . $47.7 \%$ patients had moderate to severe ischemic heart disease, in which $34.1 \%$ had coronary artery disease severe enough to require revascularisation pre TAVI. 5.7\% patients had concomitant moderate to severe valvular disease apart from aortic valve disease. The mean left ventricular ejection fraction (LVEF) was $55.8+/-12$, and $6.8 \%$ patients had a bicuspid aortic valve. 3 patients had pre TAVI pacemaker. Most patients were in sinus rhythm pre TAVI (64.8\%), 15.9\% patients had right bundle branch block and $15.9 \%$ had atrial fibrillation.

\section{Procedural characteristics}

Table 2 displays the procedural characteristics. $80 \mathrm{pa}$ tients had transfemoral TAVI, while the rest had transaortic TAVI. The majority (85.2\%) of TAVI implanted were Corevalve Evolut R (Medtronic Inc., Minneapolis, Minnesota USA), $6.8 \%$ of patients had Portico (Abbott Vascular, Abbott Park, IL, USA) valves implanted and $7 \%$ of patients had Hydra (Vascular Innovations Co Ltd.,

Table 1 Baseline demographics of patient population.

Baseline $(N=88)$

Age

$80.3+/-6.9$

STS score breakdown $(\mathrm{N}=88)$

Mean STS score $\quad 9.25$

PROM $>8 \%$

$44.3 \%$

PROM 4-8\%

$43.2 \%$

PROM $<4 \%$

$12.5 \%$

Pre op Renal replacement therapy

$3 / 88(3.4 \%)$

Presence of Ischemic heart disease

$42 / 88(47.7 \%)$

Need for pre TAVI coronary revascularization (PCI)

$30 / 88(34.1 \%)$

LVEF $(N=82)$

$55.8+/-12 \%$

Presence of other valvular heart disease(moderate or more in severity)

Bicuspid aortic valve on echocardiogram

$5 / 88(5.7 \%)$

Pre op rhythm

Sinus rhythm

$6 / 88(6.8 \%)$

Atrial fibrillation

$57 / 88(64.8 \%)$

$14 / 88(15.9 \%)$

Complete or incomplete bundle branch block

$14 / 88(15.9 \%)$

Permanent pacemaker rhythm 
Table 2 Procedural characteristics

\begin{tabular}{ll}
\hline Procedural characteristics & \\
\hline Approach & \\
Transfemoral & $80 / 88(90.9 \%)$ \\
Transaortic & $8 / 88(9.1 \%)$ \\
TAVI valve & \\
EVOLUT $R$ & $75 / 88(85.2 \%)$ \\
PORTICO & $6 / 88(6.8 \%)$ \\
HYDRA & $7 / 88(8 \%)$ \\
Pre dilatation & $37 / 87(42.5 \%)$ \\
POst dilatation & $37 / 87(42.5 \%)$ \\
NCC depth of implantation ( $N=77)$ & $4.6+/-2.8 \mathrm{~mm}$ \\
LCC depth of implantation $(N=77)$ & $6.4+/-3.0 \mathrm{~mm}$ \\
Mean infra-annular membranous septal length $(n=57)$ & $9.3+/-1.8 \mathrm{~mm}$ \\
Implantation depth/IMS length ratio $>0.5$ & $23 / 57(40.4 \%)$ \\
\hline
\end{tabular}

Thailand) valves implanted.. $42.5 \%$ of the TAVI procedures required pre-dilatation or post dilatation respectively. The mean NCC implantation depth was $4.6+$ /$2.8 \mathrm{~mm}$ and the mean LCC implantation depth was 6.4 $+/-3.0 \mathrm{~mm}$. 57 patients had measurements of the IMS length, and the mean IMS length was $9.3+/-1.8 \mathrm{~mm}$. $40 \%$ patients had an NCC implantation depth and IMS length ratio of more than 0.5 .

\section{Survival and outcome analysis}

Table 3 displays the outcomes post TAVI. The 30 day all cause mortality rate was $5.7 \%$. The 1 year all cause mortality rate by Kaplan Meier analysis was $16.7 \%$, with 1 year all cause survival rate of $83.3 \%$ (Fig. 3). The cardiovascular death rate at 1 year was $11.9 \%$. Among the 14 mortalities at 1 year, 3 patients succumbed from disabling stroke, 3 patients had myocardial infarction and 2 patients died from severe heart failure. The commonest cause of death were sepsis (3/14), disabling stroke and myocardial infarction. The rate of major vascular complications was $8 \% .2$ patients had coronary obstruction post TAVI deployment and 1 case had an intraoperation root rupture. The 30 day disabling stroke rate was 5.7 and $6.8 \%$ patients required temporary renal replacement therapy for acute kidney injury. The 30 day PPM rate was $17.6 \%$. The device success rate was $88.6 \%$. At 1 year follow up, 1 patient (1.2\%) required repeat valvular intervention and $5 / 84(6 \%)$ of patients had moderate or severe paravalvular leak on echocardiogram. The mean gradient over the aortic valve was $8.4+/-4.4 \mathrm{mmHg}$ at 1 year follow-up echocardiogram. $8.3 \%$ of patients had repeated admissions for cardiac events such as angina, myocardial infarction or heart failure at 1 year.
Table 3 Outcomes

\begin{tabular}{|c|c|}
\hline \multicolumn{2}{|l|}{ Procedural outcomes } \\
\hline 30 day all cause mortality & $5 / 88(5.7 \%)$ \\
\hline 1 year actuarial all cause mortality & $14 / 84(16.7 \%)$ \\
\hline Kaplan Meier 1 year all cause survival & $83.3 \%$ \\
\hline \multicolumn{2}{|l|}{ Causes of death (1 year) * $n=14$} \\
\hline Sepsis & $3 / 14(21.4 \%)$ \\
\hline Renal failure & $1 / 14(7.1 \%)$ \\
\hline Pacing wire ventricular perforation & $1 / 14(7.1 \%)$ \\
\hline Root rupture & $1 / 14(7.1 \%)$ \\
\hline Myocardial infarction & $3 / 14(21.4 \%)$ \\
\hline Congestive heart failure & $2 / 14(14.5 \%)$ \\
\hline Stroke & $3 / 14(21.4 \%)$ \\
\hline Cardiovascular death at 1 year & 10/84 (11.9\%) \\
\hline Major Vascular complications & 8/88 (8\%) \\
\hline Coronary obstruction & $2 / 88(2.3 \%)$ \\
\hline 30 day disabling stroke risk & $5 / 88(5.7 \%)$ \\
\hline $\begin{array}{l}30 \text { day Acute kidney injury with renal replacement } \\
\text { therapy }\end{array}$ & $6 / 88(6.8 \%)$ \\
\hline $\begin{array}{l}\text { Device success rate (defined as single valve, with } \\
\text { no moderate to severe } P V L \text {, mean gradient }<20 \mathrm{mmHg} \text { ) }\end{array}$ & $88.6 \%$ \\
\hline 1 year Prosthetic valve endocarditis & $2 / 84(2.4 \%)$ \\
\hline 1 year Repeat valvular intervention & $1 / 84(1.2 \%)$ \\
\hline $\begin{array}{l}30 \text { Day Pacemaker rates ( } n=85 * 3 \text { cases of pre op } \\
\text { PPM excluded) }\end{array}$ & $15 / 85(17.6 \%)$ \\
\hline $\begin{array}{l}\text { Moderate or more paravalvular leak (PVL) on } \\
1 \text { year echocardiogram }\end{array}$ & $5 / 84(6.0 \%)$ \\
\hline $\begin{array}{l}\text { Repeated cardiac events (angina, MI, heart failure) } \\
\text { requiring admissions within } 1 \text { year }\end{array}$ & $7 / 84(8.3 \%)$ \\
\hline
\end{tabular}

\section{Risk factor and PPM analysis}

Severe coronary artery disease requiring revascularisation (OR: $18.2+/-0.9 ; P=0.002$ ), pre TAVI atrial fibrillation (OR $8.6+/-0.9 ; P=0.02$ ) and post op disabling stoke (OR $32.6+/-1.35 ; P=0.01$ ) were found to be associated with 1 year all-cause mortality. On log rank test, severe coronary artery disease requiring percutaneous coronary intervention (PCI) and post TAVI disabling stroke significant impacted on 1 year all cause survival on Kaplan Meier analysis (Figs. 4 \& 5). No correlation was identified between the need for PPM or moderate / severe PVL with 1 year all cause survival. The commonest indication for PPM implantation post TAVI was complete heart block / type III atrioventricular block (AVB III), followed by new onset left bundle branch block (LBBB) with symptoms and hemodynamic disturbance (Table 4). 12 out of 15 patients had their PPM implanted within 7 days post TAVI with 10/15 (66.7\%) implanted between days $1-3$ post TAVI. We analysed baseline ECG and pacemaker parameters during follow up and found that $6 / 15$ (40\%) patients with PPM 
1 year all cause survival post TAVI

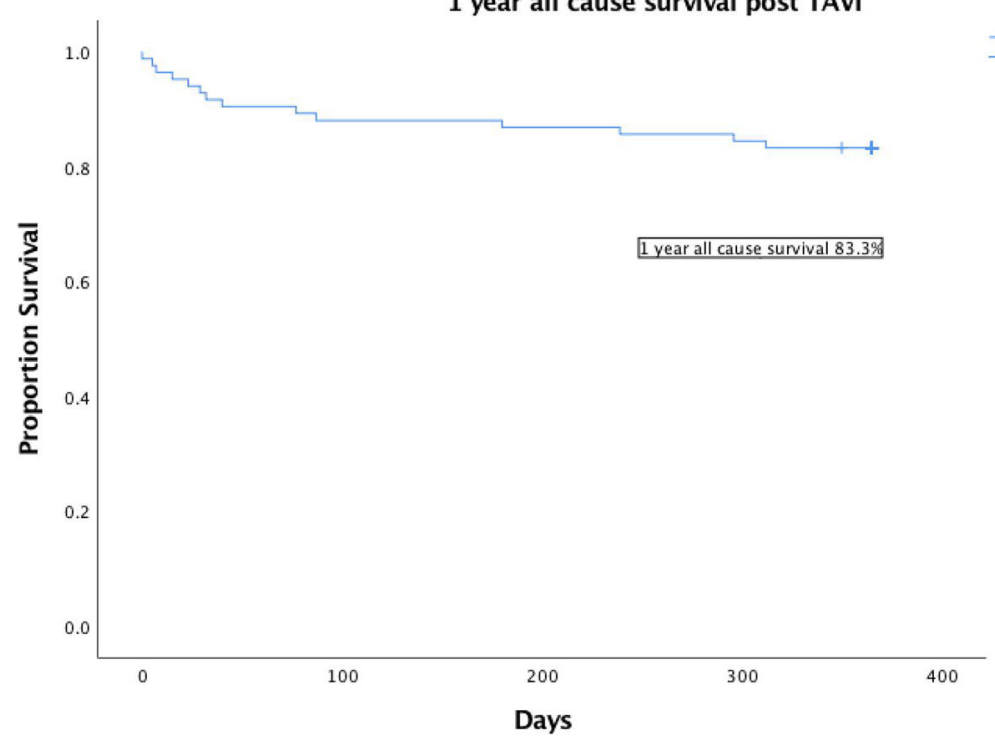

$\neg$ Survival Function

implanted post TAVI were not considered to be pacemaker dependent on 1 year follow up. Amongst the 8 patients who had AVB III post TAVI with PPM, 3 / $8(38 \%)$ were not dependent on pacemaker at 1 year. 5 out of the 12 patients (41.7\%) with PPM implanted within 7 days post TAVI were not pacemaker dependent at 1 year.

Presence of right bundle branch block (OR: $7.75+/-$ $0.65 ; P=0.002)$, NCC implantation depth (OR: $1.30+/-$ $0.12 ; P=0.03)$ and a NCC implantation depth/IMS ratio $>0.5 \quad(11.3+/-1.12 ; \quad \mathrm{P}=0.03) \quad$ correlated with increased PPM implantation rates on univariate analysis. A longer IMS length (OR: $0.58+/-0.21 ; P=0.01$ ) was associated with a lower risk of PPM implantation. On multivariate analysis, pre TAVI RBBB (OR: $11.1+/-$ 0.86: $P=0.005$ ) and a deep NCC implantation depth (OR: $1.34+/-0.15 ; P=0.048$ ) were associated with increased risk for PPM implantation. Among the $57 \mathrm{pa}-$ tients with measured IMS length, a NCC implantation depth/IMS length $>0.5$ (OR: $29.9+/-1.72 ; P=0.05)$ was found to be related to higher PPM risks on multivariate analysis.

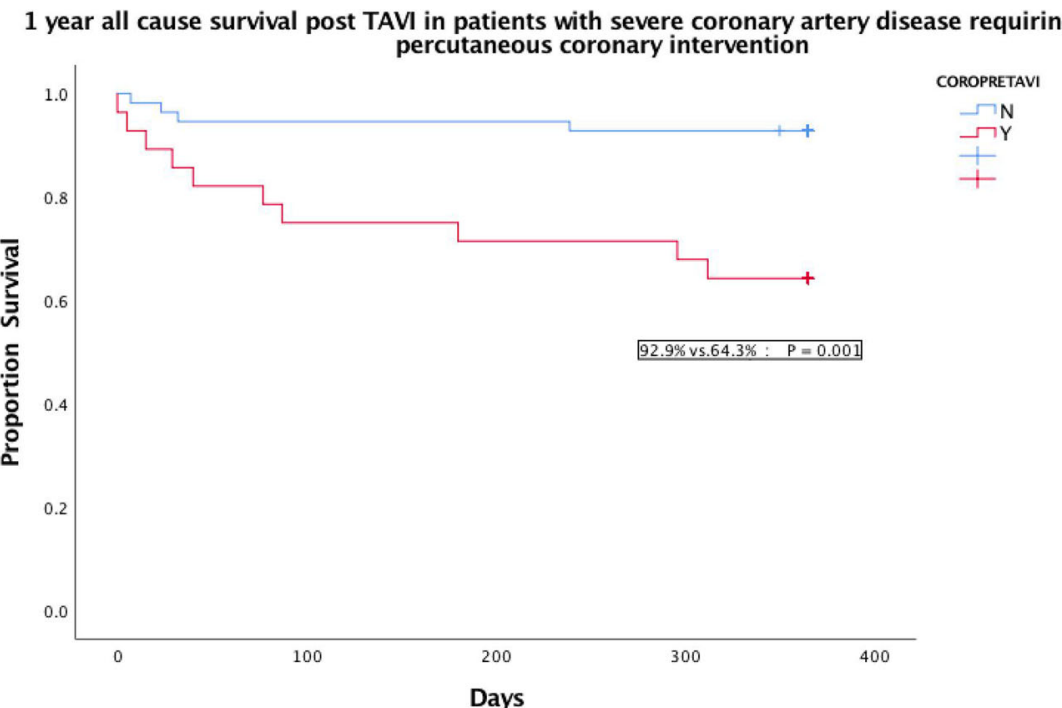

Fig. 4 Kaplan Meier analysis of all cause survival post TAVI in patients with severe coronary artery disease requiring pre TAVI percutaneous coronary intervention 
1 year all cause survival post TAVI in patients with post TAVI disabling stroke

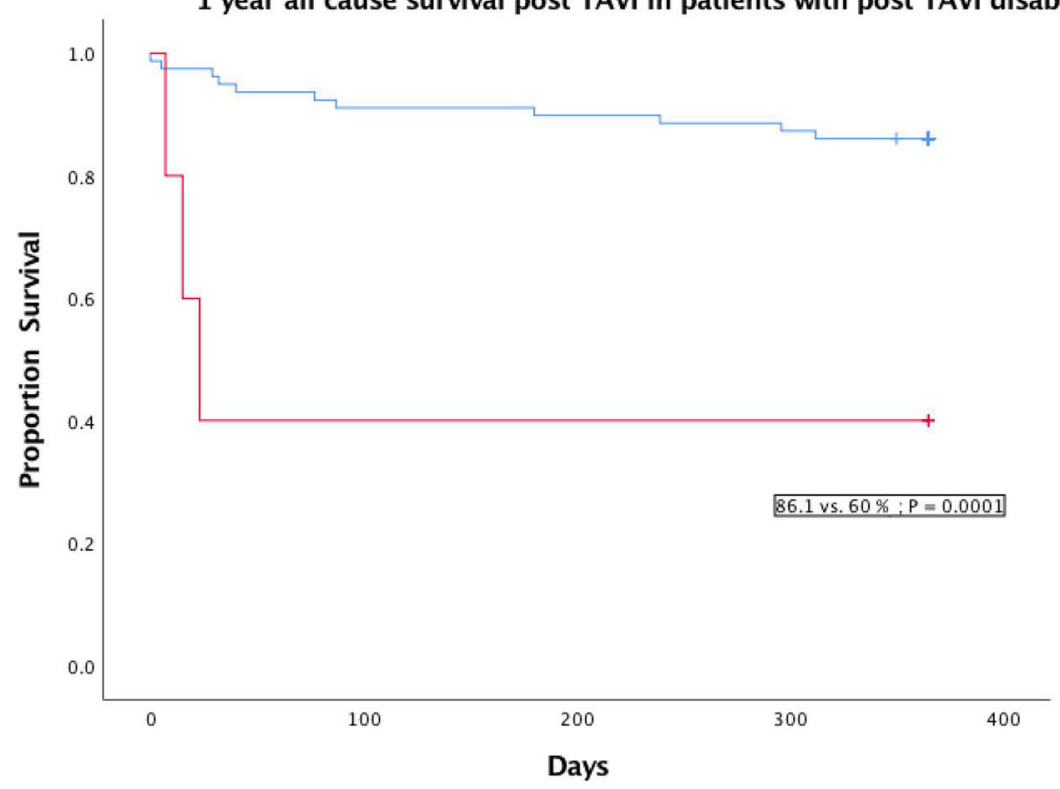

STROKEPOST

$\neg \mathrm{N}$

$\neg \mathrm{Y}$

$+$

\section{Discussion}

TAVI has firmly established itself as a mainstay treatment for patients with severe AS, and there is ample evidence supporting its safety and efficacy in patients at intermediate to high risk for SAVR. The PARTNER trials and the Corevalve trials have substantiated the role of TAVI in treatment of severe AS, and outcomes have been superior to SAVR. In our series, the device success rate was up to $88.6 \%$, with a 30 day mortality of $5.7 \%$. The 1 year all cause mortality rate was around $16.7 \%$, and considering that most patients were octogenarians with high STS scores, we have demonstrated the safety and efficacy of TAVI in our centre. These survival outcomes are consistent with those reported in the high risk Corevalve study [8], and we expect outcomes to further improve as we move down the risk ladder to treat patients at low risk with low STS scores.

Nonetheless, we cannot discount the fact that most comparative trials between TAVI and SAVR included elderly patients and have excluded bicuspid aortic valves or valves with dense LVOT calcium. In addition, the issue of durability of TAVI valves and high pacemaker rates remain unanswered, and inevitably plays a significant role in deciding the use of TAVI in younger patients. As of today, SAVR remains the gold standard treatment for young patients at low risk of SAVR [9]. In our series, the PPM rate post TAVI was $17.6 \%$. This rate was similar to the number from the TVT registry $(16.6 \%$ for Evolut R) for self-expandable valves [10]. Multiple trials have reported varying rates of post TAVI PPM, with seemingly lower rates of PPM with balloon expandable valves versus self-expandable valves, but the rates still remain high compared to SAVR. Reported rates of PPM post TAVI range from 10 to $30 \%$, which is unacceptably higher than the $3-6 \%$ of PPM in SAVR. Although randomized controlled trials have not demonsrated that the need for PPM negatively impacted survival comparing to SAVR, a recent 21 study meta-analysis on 42,927 patients have found that new onset LBBB and PPM implantation after TAVI were associated with an increased risk of all cause death and heart failure hospitalization at 1 year of follow up. The meta- analysis also concluded that new onset LBBB resulted in increased risk of cardiac death within 1 year post TAVI [5]. It is worth nothing that long term high quality studies are lacking concerning the effects new PPM implantation have on survival and cardiac events and function, and there is conflicting evidence suggesting otherwise. The REPRISE III trial, a randomized controlled trial between the LOTUS valve and Corevalve did not demonstrate worse clinical outcomes with new PPM [11].

Nonetheless, the lack of conclusive evidence relating new PPM to worse TAVI outcomes should not affect our resolve to further improve TAVI results in terms of reducing PPM rates. Numerous studies have looked into risk factors predisposing patients to a higher risk of PPM post TAVI and factors can be summarised as pre, intra and post procedural., Right bundle branch block is the most well established pre procedural risk factor for pacemaker implasntation post TAVI. For intraprocedural factors the use of self-expandable valves and a deeper implantation depth are associated with higher PPM 
Table 4 Post TAVI pacemaker implantation analysis

\begin{tabular}{|c|c|}
\hline \multicolumn{2}{|l|}{ Post TAVI PPM analysis $(n=15)$} \\
\hline \multicolumn{2}{|l|}{ Indications } \\
\hline AVB type III & $8 / 15(53.3 \%)$ \\
\hline$\angle B B B, H R<40$ bpm; symptoms & $3 / 15(20 \%)$ \\
\hline Tachy-brady syndrome with rate $<40$ bpm & $1 / 15(6.7 \%)$ \\
\hline Slow Atrial fibrillation < 40 bpm; hypotension & $1 / 15(6.7 \%)$ \\
\hline $\begin{array}{l}\text { Slow Atrial fibrillation; } \\
\text { long pause }>5 \mathrm{~s}\end{array}$ & $1 / 15(6.7 \%)$ \\
\hline Junctional/ Atrial fibrillation, with $H R<40 \mathrm{bpm}$ & $1 / 15(6.7 \%)$ \\
\hline$D D D R$ & 5/15 (33.3\%) \\
\hline WIR & $10 / 15(66.6 \%)$ \\
\hline \multicolumn{2}{|l|}{ Timing for PPM post TAVI } \\
\hline Within $24 \mathrm{~h}$ & $4 / 15(26.7 \%)$ \\
\hline D1-D3 & $6 / 16(37.5 \%)$ \\
\hline$>D 3-D 7$ & 5/15 (33.3\%) \\
\hline More than 1 week & $3 / 15(20 \%)$ \\
\hline$V P \& A P<5 \%$ at 1 year of interrogation & $6 / 15(40 \%)$ \\
\hline - AVB III as indication & $3 / 6$ \\
\hline - Tachy-brady & $1 / 6$ \\
\hline - Long pause & $1 / 6$ \\
\hline - Slow $A F+\angle B B B+$ rate $<40$ & $1 / 6$ \\
\hline \multicolumn{2}{|c|}{$\begin{array}{l}\text { Time for implant post TAVI for patients with VP/AP }<5 \% \text { \& ECG native } \\
>60 \text { bpm at Follow up }\end{array}$} \\
\hline - Within $24 h$ & $2 / 6$ \\
\hline - D1 to D3 & $1 / 6$ \\
\hline - D3 to D7 & $2 / 6$ \\
\hline - More than 1 week & $1 / 6$ \\
\hline
\end{tabular}

risks. For post procedural factors, the occurrence of LBBB, AVB III and the need for rate control drugs have been reported to increase risks for PPM $[12,13]$. In our study, we have identified RBBB and NCC depth as major predictors for post TAVI PPM. Jilaihawi et al. first reported the relationship between membranous septal length and the risk of PPM post TAVI. The PPM rate in their series with self-expandable valves was $9.7 \%$ and they found that by adopting an anatomically guided MIDAS (minimizing depth according to the membranous septum) approach to device implantation, aiming for an implantation depth less than the IMS length, could reduce need for PPM post TAVI [14]. In our study, we retrospectively measured the coaxial distance between the annulus and muscular ventricular septum on coronal cuts on CT scan and labelled the distance as infraannular membranous septal (IMS) length. We found that the longer the IMS length, and the deeper the NCC implantation depth in relation to the IMS length predicted need for PPM. It is our postulation that by actively trying to position the TAVI valve as high as possible in relation to the IMS length can reduce the need for PPM post TAVI.

The REPRISE III trial demonstrated that pacemaker dependency was a dynamic phenomenon in which a majority of post TAVI patients with PPM implanted within 30 days post procedure were not pacemaker dependent. $20-40 \%$ changed dependency status at 1 year of followup. In our series, we analysed the pacing parameters upon follow up in all pacemaker patients and found that 6 out of 15 (40\%) patients with new PPM were not pacemaker dependent based on our definition. Although there is no set criteria or definition for pacemaker non dependence. All 6 patients had a baseline ECG rate of 60 or above with $\% \mathrm{Ap} / \mathrm{Vp}<5 \%$ on pacemaker interrogation. Amongst the 12 patients who had their PPM implanted within 7 days post TAVI, $41.7 \%$ of them were not dependent on PPM at 1 year. Retrospectively, if we had waited for more than 7 days before implanting PPM in these patients we would have avoided 5 cases of PPM implantation, which would have reduced the rate of PPM to $11.7 \%$ from $17.6 \%$. This finding has prompted us to rethink the timing of PPM implantation in TAVI patients, as it is common practice to defer PPM implantation to at least 7 days post SAVR. In our centre, more emphasis is put on early mobilization and discharge of patients post TAVI, and with a strong and readily available pacing team as support, there is a tendency to implant pacemakers more aggressively and early post TAVI. Perhaps it is time for us to adopt a more patient approach for post TAVI patients with new onset conduction disturbances before prematurely implanting PPM. In addition, more studies are needed to delve into factors that cause pacemaker dependence rather the risks of new onset conduction disturbance, as modifying factors that perpetuate pacemaker dependence may impact more on clinical practice.

The commonest conduction disturbance post TAVI is $\mathrm{LBBB}$, and it is postulated to be related to pressure necrosis of the bundlecccnd NCC. It is not well understood why a repositionable, recapturable self-expandable valve has higher PPM rates than a self-centering balloon expandable valve. It is believed that the self expandable valve compresses the left ventricular outflow tract while the balloon expandable valve lands above that area and does not press on the his bundle as much. A recent large French registry has shown the SAPIEN 3 valve (Edwards Lifesciences Corporation, Irvine, California, USA) to have lower pacemaker rates than the Evolut R [15] . To date, there is no conclusive evidence showing superiority of $\mathrm{BE}$ valves over $\mathrm{SE}$ valves, but it appears preliminary data are strengthening the case of choosing a $\mathrm{BE}$ valve for patients at high risk of post TAVI PPM. Newer valve designs have emerged that rely less on LVOT/annulus radial expansion for anchoring and more on leaflet or 
supra-annular anchoring mechanisms [16, 17]. This was supposed to mitigate the risk of low valve implantation onto the LVOT causing conduction disturbances leading to PPM implantation, but so far more data are needed to substantiate this claim.

This study is retrospective in nature and has inherited intrinsic weaknesses such as recall bias, measurement bias and a lack of a comparison group. The population is relatively small and the findings relating to risk analysis are at best hypothesis generating. The measurement of the IMS length was liable to measurement error, as the quality of CT scans from different centres differed. The definition of pacemaker dependence could have been more stringent, but since the study was retrospective in nature, we were not able to proactively turn down the pacing rate to determine real dependence. This might potentially underestimate the rate of nondependence.

\section{Conclusions}

TAVI is safe and effective in patients with severe AS at intermediate to high risk for SAVR. Device success rates are high and outcomes are satisfactory. However, pacemaker rates remain high and there is a need to improve TAVI outcomes in order to fully realize the potential of TAVI in younger patients at low risk for SAVR. Pre TAVI RBBB and NCC implantation depth were important risk factors for post TAVI PPM. We have found an increased risk of PPM implantation post TAVI when the NCC implantation depth occupied more than $50 \%$ of the membranous septal length. We propose consideration of the IMS length during device implantation in patients at high risk of PPM implantation. More studies are needed to determine the optimal timing for PPM implantation and risk factors of PPM dependency post TAVI.

\section{Abbreviations \\ AS: Aortic stenosis; AVB: Atrioventricular block; BE: Balloon expandable; IMS: Infra-annular membranous septum; LCC: Left coronary cusp; LVEF: Left ventricular ejection fraction; LVOT: Left ventricular outflow tract; MIDA S: Minimizing depth according to the membranous septum; mRS: Modified Rankin score; NCC: Non coronary cusp; PCl: Percutaneous coronary intervention; PPM: Permanent pacemaker; PVL: Paravalvular leak; RCC: Right coronary cusp; RBBB: Right bundle branch block; SAVR : Surgical aortic valve replacement; SE: Self expandable; TAVI: Transcatheter aortic valve implantation}

\section{Acknowledgements}

Not applicable.

\section{Authors' contributions}

CCY is the corresponding author and was responsible for the conception,design, collection and analysis of data and writing of the final manuscript. WHL was responsible for administrative support, collection and assembly of data, and writing of final manuscript. CSH was responsible for analysis and interpretation of data. LPW was responsible for manuscript writing and interpretation of data. CKL was responsible for assembly of data, analysis of data and interpretation of data. SCYwas responsible for provision of patients and study materials, analysis and interpretation of data and writing of manuscript. WEB was responsible for administrative support, provision of patients, assemble of data, analysis and interpretation of data and writing of manuscript. All authors read and approved the manuscript.

\section{Author's information}

Not applicable.

Funding

The authors declare that there is no external funding support for this study.

\section{Availability of data and materials}

The datasets used and/or analysed during the current study are available from the corresponding author on reasonable request.

\section{Ethics approval and consent to participate}

Ethical Statement: The authors are accountable for all aspects of the work in ensuring that questions related to the accuracy or integrity of any part of the work are appropriately investigated and resolved. This cardiac surgical local registry was approved by the Hong Kong.

Hospital Authority and the Government of Hong Kong SAR to allow collection, analysis, reporting and outcome tracking of patient data since its introduction in 2007.

\section{Consent for publication}

No informed consents from patients were sought for this retrospective analysis as there were no identifiers in this manuscript that could disclose individual patient confidentiality. All patient data had been secured and kept confidential.

\section{Competing interests}

The authors declare that they have no competing interests.

\section{Author details}

${ }^{1}$ Division of Cardiothoracic Surgery, Department of Surgery, The Chinese University of Hong Kong, Prince of Wales Hospital, 30-32 Ngan Shing Street, Shatin, New Territories, Hong Kong. ${ }^{2}$ Division of Cardiology, Department of Medicine, The Chinese University of Hong Kong, Prince of Wales Hospital, 30-32 Ngan Shing Street, Shatin, New Territories, Hong Kong.

Received: 1 May 2020 Accepted: 20 July 2020

Published online: 29 July 2020

\section{References}

1. Mack MJ, Leon MB, Thourani VH, et al. Transcatheter aortic-valve replacement with a balloon-expandable valve in low-risk patients. N Engl J Med. 2019;380:1695-705.

2. Popma JJ, Deeb GM, Yakubov SJ, et al. Transcatheter aortic-valve replacement with a self-expanding valve in low-risk patients. N Engl J Med. 2019; 380:1706-1715.

3. Thyregod $\mathrm{HGH}$, Ihlemann $\mathrm{N}$, Jørgensen $\mathrm{TH}$, Nissen $\mathrm{H}$, Kjeldsen BJ, Petursson $P$, Chang $Y$, Franzen OW, Engstrøm T, Clemmensen P, Hansen PB, Andersen LW, Steinbrüchel DA, Olsen PS, Søndergaard L. Five-year clinical and echocardiographic outcomes from the NOTION randomized clinical trial in patients at lower surgical risk. Circulation. 2019 Feb 1. https://doi.org/10. 1161/circulationaha.118.036606.

4. Van Rosendael PJ, Delgado V, Bax JJ. Pacemaker implantation rate after transcatheter aortic valve implantation with early and new generation devices : a systemic review. Eur Heart J. 2018;39:2003-13.

5. Faroux L, Chen S, Muntane-Carol G, et al. Clinical impact of conduction disturbances in transcatheter aortic valve replacement recipients: a systemic review and meta-analysis. European Heart Journal,ehz924,https://doi.org/10. 1093/eurheartj/ehz924

6. Thourani VH, Suri RM, Gunter RL, et al. Contemporary real world outcomes of surgical aortic valve replacement in 141,905 low-risk, interemediate -risk and high-risk patients. Ann Thorac Surg 2015;99: 55-61.

7. Kappetein AP, Head SJ , Genereux P, et al. Updated standardized endpoint definitions for transcatheter aortic valve implantation : the Valve Academic Consortium-2 consensus document (VARC -2). Eur J Cardiothorac Surg. 2012 ; Nov; 42 (5): S45-60.

8. Adams DH, Popma JJ, Reardon MJ, et al. Transcatheter aortic-valve replacement with a self-expanding prosthesis. N Engl J Med. 2014;370:1790-8. 
9. Nishimura RA, Otto CM, Bonow RO, et al. 2017 AHA/ACC focused update of the 2014 AHA/ACC guideline for the management of patients with valvular heart disease: a report of the American College of Cardiology/American Heart Association task force on clinical practice quidelines. J Am Coll Cardiol. 2017;70:252-89.

10. Sorajja P, Kodali S, Reardon MJ, et al. Outcomes for the commercial use of self expanding prostheses in transcatheter aortic valve replacement. A report from the STS/ ACC TVT registry. J Am Coll Cardiol Intv. 2017;10:2090-8.

11. Meduri CU, Kereiakes DJ, Rajagopal V, et al. Pacemaker Implantation and dependency after transcatheter aortic valve replacement in the REPRISE III trial. J Am Heart Assoc. 2019;8:e012594. DOI : 10.1161.

12. Siontis GC, Juni P, Pilgrim T, Stortecky S, Bullesfeld L, Meier B, Wenaweser $P$, Windecker $S$. Predictors of permanent pacemaker implantation in patients with severe aortic stenosis undergoing TAVR: a meta-analysis. J Am Coll Cardiol. 2014:64:129-40.

13. Fadahunsi OO, Olowoyeye A, Ukaigwe A, Li Z, Vora AN, Vemulapalli S, Elgin E, Donato A. Incidence, predictors, and outcomes of permanent pacemaker implantation following transcatheter aortic valve replacement: analysis from the U.S. Society of Thoracic Surgeons/American College of Cardiology TVT registry. JACC Cardiovasc Interv. 2016;9:2189-99.

14. Jilaihawi $H$, Zhao Z, Du R, et al. Minimizing permanent pacemaker following repositionable self- expanding transcatheter aortic valve replacement. JACC Cardiovasc Interv. 2019 Sep 23;12(18):1796-807.

15. Van Belle E, Vincent F, Labreuche J, et al. Balloon- expandable versus selfexpanding transcatheter aortic valve replacement: a propensity -matched comparison from the France-TAVI registry. Circulation. 2020;141:243-59.

16. Hamm K, Reents W, Zacher M, Kerber S, Diegeler A, Schieffer B, Barth S. Transcatheter aortic valve implantation using the ACURATE TA and ACUR ATE neo valves: a 4-year single-center experience. Eurolntervention. 2017;13: 53-9.

17. Silaschi M, Treede H, Rastan AJ, Baumbach H, Beyersdorf F, Kappert U, Eichinger W, Ruter F, de Kroon TL, Lange R, Ensminger S, Wendler O. The JUPITER registry: 1-year results of transapical aortic valve implantation using a second-generation transcatheter heart valve in patients with aortic stenosis. Eur J Cardiothorac Surg. 2016;50:874-81.

\section{Publisher's Note}

Springer Nature remains neutral with regard to jurisdictional claims in published maps and institutional affiliations.

Ready to submit your research? Choose BMC and benefit from:

- fast, convenient online submission

- thorough peer review by experienced researchers in your field

- rapid publication on acceptance

- support for research data, including large and complex data types

- gold Open Access which fosters wider collaboration and increased citations

- maximum visibility for your research: over $100 \mathrm{M}$ website views per year

At $\mathrm{BMC}$, research is always in progress.

Learn more biomedcentral.com/submissions 